\title{
Optimasi Konsentrasi Etil Selulosa dan Lama Pengadukan dalam Preparasi Microspheres Metformin Hidroklorida
}

\author{
Ninda Sukmaningrum, Lusia Oktora Ruma Kumala Sari dan Eka Deddy Irawan \\ Fakultas Farmasi, Universitas Jember, Indonesia
}

\begin{abstract}
Abstrak
Metformin hidroklorida $(\mathrm{MH})$ merupakan obat pilihan pertama yang digunakan dalam terapi diabetes mellitus tipe 2, namun dapat menimbulkan efek samping pada saluran pencernaan sehingga MH tepat dipreparasi menjadi sediaan microspheres. Banyak faktor yang mempengaruhi hasil preparasi microspheres di antaranya adalah konsentrasi etil selulosa (EC) dan lama pengadukan yang digunakan. Penelitian ini bertujuan untuk mengetahui komposisi terbaik konsentrasi EC dan lama pengadukan yang dapat menghasilkan microspheres MH-EC dengan entrapment efficiency (EE) tertinggi menggunakan optimasi desain faktorial. $\mathrm{MH}$ digunakan sebagai bahan aktif, EC digunakan sebagai polimer serta non-aqueous solvent evaporation method sebagai teknik yang dipilih dalam preparasi microspheres. Hasilnya microspheres yang menggunakan konsentrasi EC sebanyak $4.500 \mathrm{mg}$ dan lama pengadukan selama 2 jam menghasilkan EE sebesar 84,6 \pm 0,557\% dengan nilai verifikasi EE sebesar 98,1\%, drug loading sebesar $12,7 \pm 0,173 \%$ dan yield sebesar 95,1 $\pm 0,612 \%$. Microspheres memiliki bentuk sferis dan morfologi permukaan yang relatif halus dan cerah serta ukuran partikel sebesar 173,8 $\pm 4,41 \mu \mathrm{m}$. Hasil analisis FTIR menunjukkan bahwa tidak ada perubahan gugus fungsi spesifik pada $\mathrm{MH}$ sebagai bahan aktif.
\end{abstract}

Kata kunci: microspheres, metformin hidroklorida, etil selulosa

\section{Optimization of Ethyl Cellulose Concentration and Stirring Time on Metformin Hydrochloride Microspheres}

\begin{abstract}
Metformin hydrochloride ( $\mathrm{MH}$ ) has been used as a first line for treatment of diabetes mellitus type 2. It could cause gastrointestinal side effects, therefore it is appropriate to be prepared as microspheres. Many factors affect the result of microspheres preparation, such as EC concentration and stirring time which used in preparation. This research was aimed to find the best composition of ethyl cellulose (EC) concentration and stirring time to produce $\mathrm{MH}-\mathrm{EC}$ microspheres with the highest entrapment efficiency (EE) using factorial design optimization. $\mathrm{MH}$ was used as a drug, EC was used as a polymer and non-aqueous solvent evaporation method was chosen for technique of microspheres preparation. The result of microspheres preparation used 4,500 $\mathrm{mg}$ of EC and 2 hours stirring time produced $84.6 \pm 0.557 \%$ EE, 98.1\% EE verification, $12.7 \pm 0.173 \%$ drug loading and $95.1 \pm 0.612 \%$ yield. The microspheres had spherical structure and a relatively smooth and bright surface morphology. The particle size was $173.8 \pm 4.41 \mu \mathrm{m}$. FT-IR analysis indicated that there were no changes in the spesific functional groups on $\mathrm{MH}$ as an active substance.
\end{abstract}

Keywords: microspheres, metformin hydrochloride, ethyl cellulose

Korespondensi: Ninda Sukmaningrum nindasukma1@gmail.com 


\section{Pendahuluan}

Metformin hidroklorida (MH) adalah obat yang direkomendasikan American Diabetic Association dan European Association for the Study of Diabetes sebagai first line terapi diabetes mellitus tipe $2 .{ }^{1}$ Umumnya dosis $\mathrm{MH}$ pada sediaan konvensional yang digunakan yaitu sebesar $500 \mathrm{mg}$ untuk pemakaian 2-3 kali sehari atau $850 \mathrm{mg}$ untuk pemakaian sekali atau dua kali sehari dengan bioavailabilitas sebesar 50\%$60 \%$ dan waktu paruh yang pendek yaitu 1,5 4,5 jam. $^{2}$

Penggunaan $\mathrm{MH}$ dengan dosis yang besar dan secara berulang memungkinkan terjadinya gangguan gastrointestinal dan toksisitas sebanyak $30 \%{ }^{3}$ Efek samping yang dapat ditimbulkan yaitu seperti perut terasa tidak nyaman, mual dan diare. ${ }^{4}$ Sebagai solusi dari permasalahan tersebut, maka dikembangkan sistem pelepasan obat terkendali yang dapat melepaskan obat secara perlahan pada saluran gastrointestinal sehingga akan memperpanjang durasi pelepasan obat dan meningkatkan kenyamanan pasien. ${ }^{5}$

Microspheres merupakan salah satu teknologi farmasi dalam sistem penghantaran obat terkendali yang menggunakan bahan polimer sebagai pembawa. ${ }^{6}$ Microspheres adalah partikel solid yang memiliki rentang

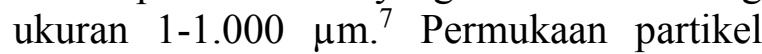
microspheres yang memiliki pori-pori mampu melepaskan bahan aktif secara perlahan dan menghasilkan partikel dalam ukuran mikron. ${ }^{8}$

Metode solvent evaporation telah mendapatkan banyak perhatian dan lebih disukai dalam pembuatan microspheres untuk sistem penghantaran obat terkendali karena kemudahan dalam fabrikasi dan tanpa menurunkan aktivitas dari bahan aktif. ${ }^{9}$ Salah satu tipe dari metode solvent evaporation adalah non-aqueous solvent evaporation. Metode ini tidak menggunakan air sebagai pelarut sehingga cocok digunakan sebagai metode pembuatan microspheres dengan bahan obat yang bersifat larut air. Preparasi microspheres dengan teknik non aqueous solvent evaporation menggunakan $\mathrm{MH}$ sebagai bahan aktif dan etil selulosa sebagai bahan polimer. ${ }^{7}$

Rumus molekul $\mathrm{MH}$ adalah $\mathrm{C}_{4} \mathrm{H}_{11} \mathrm{~N}_{5} . \mathrm{HCl}^{10}$ Aksi dari $\mathrm{MH}$ yaitu meningkatkan sensitivitas insulin sehingga terjadi peningkatan uptake glukosa. Penggunaan $\mathrm{MH}$ dapat menurunkan kadar gula darah pasien sebesar 60 hingga 80 $\mathrm{mg} / \mathrm{dL}$, selain itu penggunaan $\mathrm{MH}$ juga tidak beresiko menimbulkan hipoglikemi. ${ }^{11}$ Struktur MH dapat dilihat pada Gambar 1.

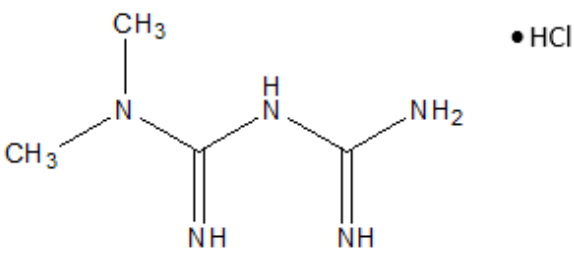

Gambar 1 Struktur MH mengandung gugus biguanida yang tersubstitusi dua gugus metil ${ }^{10}$

Etil selulosa (EC) merupakan polimer tak larut air yang banyak digunakan pada berbagai sediaan lepas lambat untuk bahan aktif yang larut air. ${ }^{7}$ EC banyak digunakan sebagai polimer dalam sediaan farmasi karena bersifat biokompatibel dan merupakan polimer selulosa yang non toksik. ${ }^{12}$ EC bersifat mukoadesif dan secara luas digunakan sebagai bahan pembawa untuk berbagai bentuk sediaan serta diketahui stabil terhadap cahaya, panas, oksigen ataupun kelembaban. ${ }^{13}$

Entrapment efficiency (EE) merupakan salah satu faktor keberhasilan suatu preparasi microspheres. Nilai EE digunakan untuk menunjukkan seberapa besar jumlah obat yang terjerap di dalam partikel microspheres. Banyak faktor yang mempengaruhi nilai EE. 
Menurut penelitian yang dilakukan oleh Maji et $a l .{ }^{7}$ dan Rathod et al. ${ }^{14}$ terdapat hubungan antara jumlah EC dan lama pengadukan yang digunakan terhadap nilai EE pada microspheres yang dihasilkan. Berdasarkan hal tersebut maka perlu dilakukan optimasi konsentrasi EC dan lama pengadukan untuk memperoleh respon EE tertinggi.

\section{Metode}

Bahan yang digunakan dalam penelitian ini adalah $\mathrm{MH}$ sebagai bahan aktif (Zenith Pharmaceutical), EC sebagai polimer (Lawsim Zecha), metanol sebagai fase internal (Brataco Chemika), aseton sebagai fase internal (Smart Lab. Indonesia), parafin cair sebagai fase eksternal (Brataco Chemika), dan petroleum eter sebagai agen pencuci (Brataco Chemika).

Penentuan jumlah formula yang akan dipreparasi dalam penelitian dilakukan menggunakan desain faktorial dua faktor dua level. Tiap formula memiliki jumlah bahan aktif yang sama, yang membedakan yaitu jumlah polimer EC yang digunakan dan lama pengadukan four blades propeller dalam preparasi microspheres $\mathrm{MH}$. Pemilihan level rendah dan level tinggi pada masing-masing faktor ditentukan berdasarkan hasil penelitian sebelumnya. Preparasi microspheres $\mathrm{MH}$-EC untuk masing-masing formula dapat dilihat pada Tabel 1.

Preparasi microspheres dengan metode non-aqueous solvent evaporation dilakukan dengan mencampurkan dispersi $\mathrm{MH}$ dalam $5 \mathrm{ml}$ metanol dengan larutan EC dalam $24 \mathrm{ml}$ aseton. Campuran tersebut dimasukkan ke dalam $50 \mathrm{ml}$ parafin cair yang mengandung span $80 \quad 2 \% \quad \mathrm{v} / \mathrm{v}$, kemudian dilakukan pengadukan menggunakan four blades propeller kecepatan $400 \mathrm{rpm}$ pada suhu ruang. Microspheres yang terbentuk disaring dengan menggunakan penyaring vakum dilengkapi kertas Whatman no 1. Serbuk microspheres yang terbentuk dicuci menggunakan petroleum eter suhu $50^{\circ} \mathrm{C}$ kemudian dikeringkan dalam oven suhu $60^{\circ} \mathrm{C}$ sampai didapatkan berat microspheres yang konstan.

Tabel 1 Preparasi microspheres MH-EC: (1) konsentrasi EC $1.500 \mathrm{mg}$ dan pengadukan 2 jam; (A) konsentrasi EC $4.500 \mathrm{mg}$ dan pengadukan 2 jam; (B) konsentrasi EC $1.500 \mathrm{mg}$ dan pengadukan $4 \mathrm{jam} ;(\mathrm{AB})$ konsentrasi EC $4.500 \mathrm{mg}$ dan pengadukan 4 jam

\begin{tabular}{cccc}
\hline Formula & $\begin{array}{c}\text { MH } \\
(\mathrm{mg})\end{array}$ & $\begin{array}{c}\text { EC } \\
(\mathrm{mg})\end{array}$ & $\begin{array}{c}\text { Lama pengadukan } \\
(\mathrm{jam})\end{array}$ \\
\hline 1 & 750 & 1.500 & 2 \\
$\mathrm{~A}$ & 750 & 4.500 & 2 \\
$\mathrm{~B}$ & 750 & 1.500 & 4 \\
$\mathrm{AB}$ & 750 & 4.500 & 4 \\
\hline
\end{tabular}

Sejumlah microspheres yang setara dengan $5 \mathrm{mg} \mathrm{MH}$ dibilas menggunakan akuades untuk menghilangkan $\mathrm{MH}$ bebas. Microspheres kemudian dihancurkan dalam mortir, dilarutkan dengan akuades sampai dengan $100 \mathrm{ml}$ dan disaring. Filtrat selanjutnya diencerkan 10 kali dan dianalisis menggunakan spektrofotometer UV pada panjang gelombang $233 \mathrm{~nm}$ untuk menentukan konsentrasi obat. Cara penentuan EE yaitu dengan membandingkan konsentrasi obat sebenarnya dengan konsentrasi obat teoritis lalu dikali $100 \%$.

Nilai EE yang diperoleh dari masingmasing formula dinyatakan sebagai respon yang diamati pada penelitian ini. Respon kemudian dimasukkan dalam software design expert 10.0.0.3 versi trial untuk mendapatkan formula optimum. Berdasarkan hasil pengolahan data dapat diketahui efek faktor serta interaksinya terhadap respon, kemudian untuk mengetahui komposisi optimum kombinasi konsentrasi EC dan lama pengadukan yang menghasilkan nilai $\mathrm{EE}$ 
tertinggi dapat diketahui melalui contour plot dan overlay plot.

Formula optimum microspheres $\mathrm{MH}$ yang dihasilkan berdasarkan software design expert 10.0.0.3 versi trial selanjutnya dibuat. Verifikasi EE kemudian dilakukan untuk mengetahui seberapa besar kemiripan EE hasil prediksi dengan hasil percobaan. Formula optimum selanjutnya dilakukan karakterisasi meliputi drug loading (DL), yield, analisis fourier transform infrared (FTIR), dan scanning electron microscopy (SEM). Perhitungan DL yaitu dengan cara EE dikali berat $\mathrm{MH}$ sebenarnya dibagi dengan berat microspheres yang didapat lalu dikali $100 \%$. Nilai yield didapat dengan cara membagi berat microspheres yang didapat dari hasil preparasi dengan berat microspheres teoritis lalu dikali 100\%.

Analisis FT-IR menggunakan metode Attenuated Total Reflectance (ATR) dilakukan dengan meletakkan sampel microspheres, $\mathrm{MH}$ dan EC yang telah dihaluskan pada plat ATR. Pemeriksaan gugus fungsi dilakukan pada bilangan gelombang 400-4.000 $\mathrm{cm}^{-1}$.

SEM dilakukan dengan meletakkan sejumlah microspheres disebarkan dan ditempelkan menggunakan selotip karbon pada bagian stub lalu ditempatkan di scanning electron chamber. Scanning dilakukan pada pembesaran yang berbedabeda, maksimum 500 kali.

\section{Hasil}

Berdasarkan Gambar 2, microspheres $\mathrm{MH}$ yang dihasilkan menunjukkan bentuk yang hampir sama yaitu serbuk putih agak kekuningan. Hasil uji EE masing-masing formula ditunjukkan oleh Tabel 2.
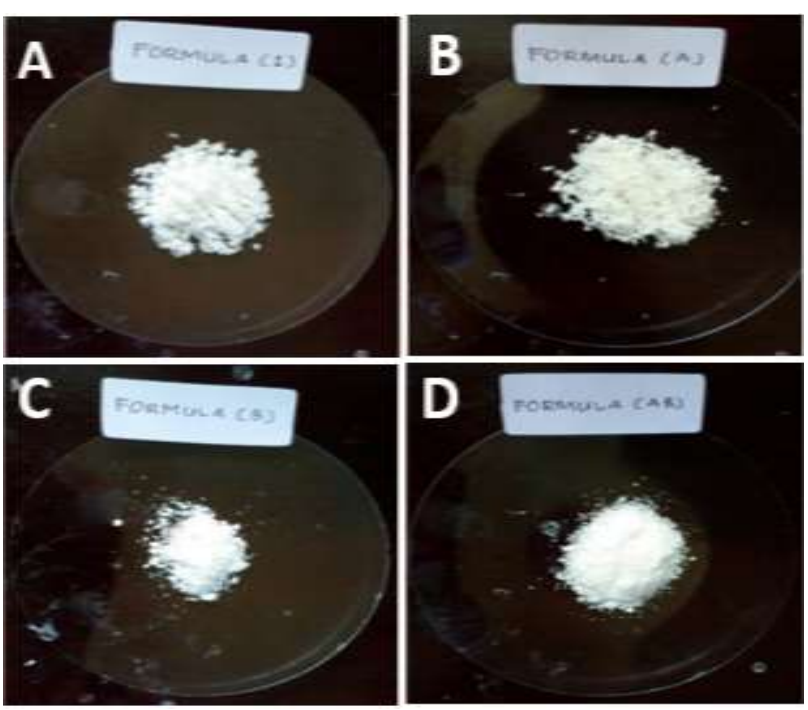

Gambar 2 Hasil pembuatan empat formula microspheres MH-EC:

(A) konsentrasi EC $1.500 \mathrm{mg}$ dan pengadukan 2 jam; (B) konsentrasi EC $4.500 \mathrm{mg}$ dan pengadukan 2 jam; (C) konsentrasi EC $1.500 \mathrm{mg}$ dan pengadukan 4 jam; (D) konsentrasi EC $4.500 \mathrm{mg}$ dan pengadukan 4 jam

Tabel 2 Hasil pengujian EE tiap formula

\begin{tabular}{cccc}
\hline $\mathrm{F}$ & $\begin{array}{c}\mathrm{EC} \\
(\mathrm{mg})\end{array}$ & $\begin{array}{c}\text { Lama pengadukan } \\
(\mathrm{jam})\end{array}$ & $\begin{array}{c}\mathrm{EE} \\
(\%)\end{array}$ \\
\hline 1 & 1.500 & 2 & $64,2 \pm$ \\
& & & 0,264 \\
$\mathrm{~A}$ & 4.500 & 2 & $83,0 \pm$ \\
& & & 0,308 \\
$\mathrm{~B}$ & 1.500 & 4 & $51,7 \pm$ \\
& & & 0,453 \\
$\mathrm{AB}$ & 4.500 & 4 & $76,1 \pm$ \\
& & & 0,529 \\
\hline
\end{tabular}

*data disajikan dalam rerata $\pm \mathrm{SD}(\mathrm{n}=3)$

Nilai EE dari masing-masing formula selanjutnya dimasukkan dalam software design expert 10.0.0.3 versi trial sehingga didapatkan Persamaan 1.

$\mathrm{EE}=+68,73+10,80 * \mathrm{~A}-4,85 * \mathrm{~B}+$ $1,42 * \mathrm{AB} \ldots . .(1)$ 
Software design expert 10.0.0.3 versi trial juga dapat memberikan contour plot dan overlay plot. Gambar contour plot dapat dilihat pada Gambar 3.

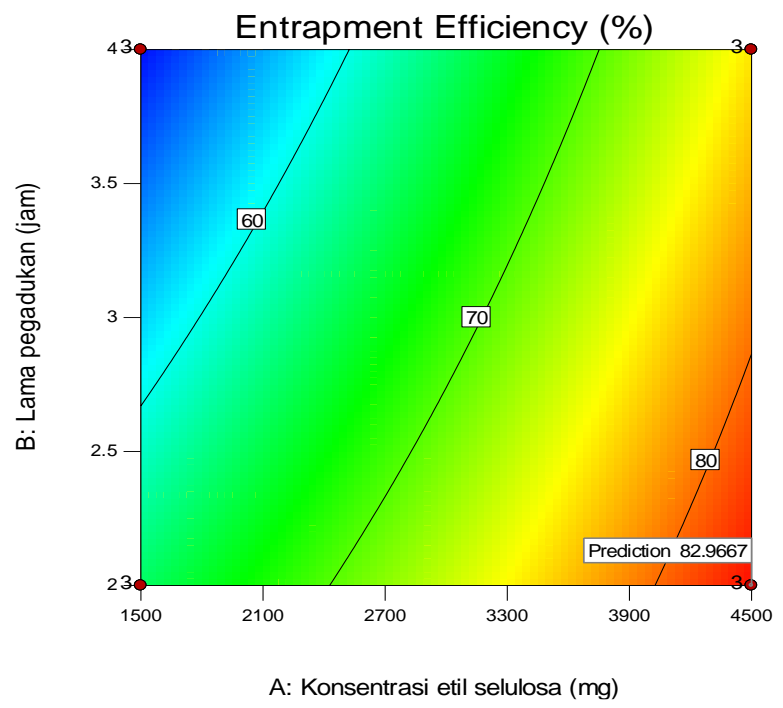

Gambar 3 Contour plot konsentrasi EC dan lama pengadukan terhadap $\mathrm{EE}$

Contour plot menggambarkan efek konsentrasi EC dan lama pengadukan terhadap EE. Daerah yang berwarna biru memiliki EE prediksi yang paling rendah sedangkan daerah berwarna merah memiliki EE prediksi yang paling tinggi. Semakin banyak jumlah EC dan semakin rendah lama pengadukan yang digunakan maka akan meningkatkan nilai EE.

Grafik overlay plot digunakan untuk menentukan daerah optimum respon EE yang ditunjukkan oleh daerah berwarna abu-abu dan kuning. Respon $\mathrm{EE}$ di atas 60\% didapatkan pada daerah berwarna kuning, sedangkan pada daerah berwarna abu-abu didapatkan respon EE di bawah 60\%. Pada daerah warna kuning dapat dibuat flag di sembarang titik yang akan menampilkan jumlah EC dan lama pengadukan beserta respon yang dihasilkan pada titik tersebut. Gambar overlay plot dapat dilihat pada Gambar 4.

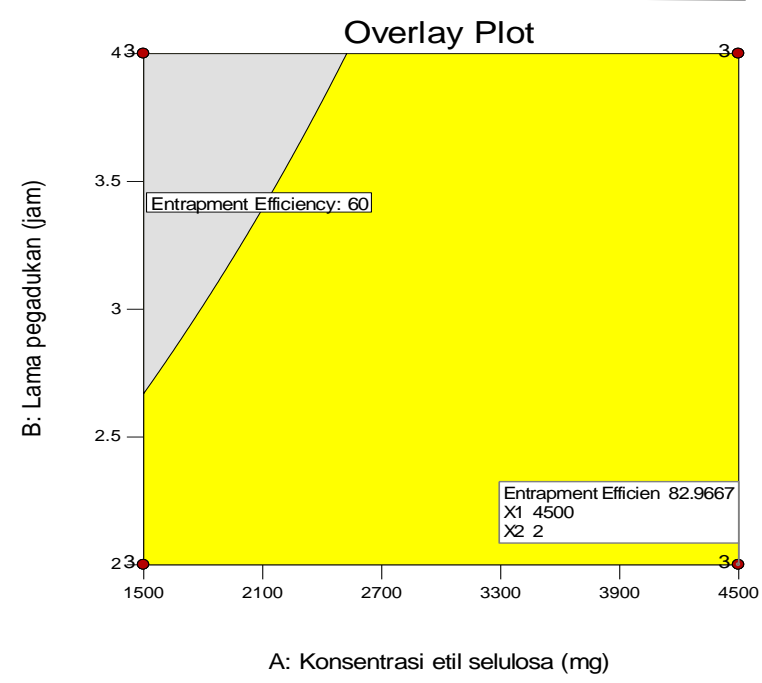

Gambar 4 Overlay plot respon EE

Hasil pengujian EE formula optimum terpilih yaitu menggunakan EC sebanyak $4.500 \mathrm{mg}$ dan lama pengadukan 2 jam yaitu sebesar 84,6 $\pm 0,557 \%$, sedangkan EE hasil prediksi software design expert 10.0.0.3 versi trial adalah sebesar 82,9667\%. Hasil verifikasi EE memberikan kemiripan sebesar 98,1\%. Hasil karakterisasi formula optimum menunjukkan bahwa microspheres $\mathrm{MH}$ memiliki nilai DL dan yield masing-masing sebesar $12,7 \pm 0,173 \%$ dan $95,1 \pm 0,612 \%$.

Hasil analisis FT-IR menunjukkan bahwa tidak ada perubahan gugus fungsi pada $\mathrm{MH}$ ditandai dengan adanya kesamaan puncak yang khas pada $\mathrm{MH}$ murni yaitu $\mathrm{N}-\mathrm{H}$ primer pada bilangan gelombang gelombang $3.369 \mathrm{~cm}^{-1}$, N-H sekunder pada bilangan gelombang $3.158 \mathrm{~cm}^{-1}$, N-H tekuk primer pada bilangan gelombang $1.626 \mathrm{~cm}^{-1}, \mathrm{~N}-\mathrm{H}$ tekuk sekunder pada bilangan gelombang $1.567 \mathrm{~cm}^{-1}$ dan $\mathrm{C}-\mathrm{N}$ pada bilangan gelombang $1060 \mathrm{~cm}^{-1}$. Hasil analisis FT-IR microspheres MH-EC ditampilkan dalam Gambar 5. 


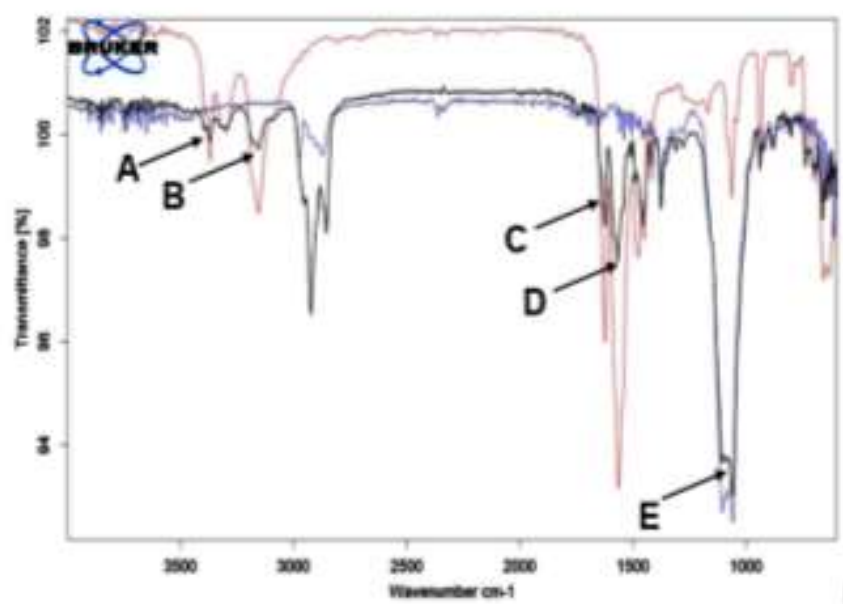

Gambar 5 Hasil spektra FT-IR MH (merah), EC (biru) dan microspheres MH-EC (hitam) menunjukkan adanya gugus fungsi yang khas pada $\mathrm{MH}$ yaitu: (A) $\mathrm{N}-\mathrm{H}$ primer pada $3.369 \mathrm{~cm}^{-1}$; (B) $\mathrm{N}-\mathrm{H}$ sekunder pada $3.158 \mathrm{~cm}^{-1}$; (C) N-H tekuk primer pada $1.626 \mathrm{~cm}^{-1}$; (D) $\mathrm{N}$ $\mathrm{H}$ tekuk sekunder pada $1.567 \mathrm{~cm}^{-1}$; (E) $\mathrm{C}-\mathrm{N}$ pada $1.060 \mathrm{~cm}^{-1}$

Hasil karakterisasi ukuran partikel, bentuk dan morfologi microspheres $\mathrm{MH}-\mathrm{EC}$ menggunakan SEM didapat rerata ukuran partikel sebesar 173,8 \pm 4,41 $\mu \mathrm{m}$. Morfologi microspheres $\mathrm{MH}-\mathrm{EC}$ memilki bentuk sferis, permukaan yang relatif halus, dan berwarna cerah. Morfologi microspheres dapat dilihat pada Gambar 6 dengan pembesaran 250x.

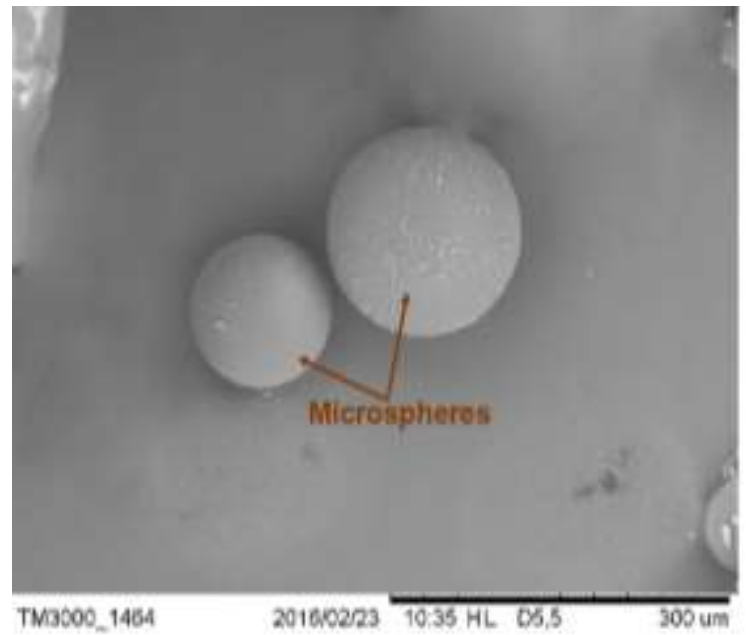

Gambar 6 Hasil analisis SEM dengan perbesaran $250 \mathrm{x}$

\section{Pembahasan}

Hasil analisis software design expert 10.0.0.3 versi trial menunjukkan bahwa konsentrasi EC dan lama pengadukan serta interaksi keduanya memiliki pengaruh yang signifikan terhadap respon EE yang didapatkan. Hal ini ditunjukkan dari persamaan yang dihasilkan dan contour plot yang menggambarkan semakin lama pengadukan yang dilakukan maka terjadi pergeseran ke arah berwarna biru, yang menunjukkan daerah dengan respon EE paling rendah. Namun, semakin tinggi konsentrasi EC yang digunakan terjadi pergeseran ke arah berwarna merah, yang menunjukkan daerah dengan respon EE paling tinggi.

Konsentrasi EC dapat mempengaruhi nilai EE yang dihasilkan. Semakin banyak jumlah polimer yang digunakan akan menyebabkan peningkatan EE. Hal ini dikarenakan semakin banyak jumlah polimer EC yang digunakan maka akan meningkatkan kemampuan polimer tersebut dalam melingkupi bahan aktif. Polimer EC bertindak sebagai lapisan yang mencegah difusi bahan aktif ke fase eksternal. ${ }^{7}$ Hal ini sejalan dengan penelitian yang dilakukan oleh Garud et al. ${ }^{15}$ bahwa peningkatan jumlah EC dapat menyebabkan peningkatan nilai EE.

Lama pengadukan juga mempengaruhi EE yang dihasilkan oleh suatu microspheres. Pengadukan yang terlalu singkat menyebabkan proses emulsi untuk pembentukan microspheres belum sepenuhnya terjadi dan bahan aktif belum sepenuhnya terjerap dalam partikel microspheres. Sebaliknya, proses pengadukan yang terlalu lama dapat menyebabkan penurunan EE karena adanya penurunan ukuran partikel microspheres yang diperoleh. Penurunan ukuran partikel menyebabkan penurunan kemampuan microspheres dalam menjerap bahan aktif 
sehingga akan menurunkan EE. Hal ini sejalan dengan penelitian yang dilakukan oleh Rathod et al. bahwa peningkatan lama pengadukan yang dilakukan dapat menurunkan nilai EE. ${ }^{14}$

Formula optimum terpilih yaitu formula dengan $\mathrm{EE}$ prediksi tertinggi. Berdasarkan Gambar 4. Dipilih formula optimum dengan faktor konsentrasi EC sebesar $4.500 \mathrm{mg}$ dan faktor lama pengadukan 2 jam yang diprediksi menghasilkan EE sebesar 82,9667\%. Hasil verifikasi $\mathrm{EE}$ formula optimum didapatkan hasil bahwa EE hasil percobaan memiliki nilai yang berdekatan dengan $\mathrm{EE}$ hasil prediksi.

Karakterisasi DL digunakan untuk menunjukkan seberapa efisien formula yang digunakan. DL yang didapatkan dari formula optimum memiliki nilai yang berdekatan dengan penelitian yang dilakukan oleh Maji et al. ${ }^{7}$

Karakterisasi yield digunakan untuk mengetahui seberapa efisien metode yang digunakan sehingga membantu menentukan metode pembuatan microspheres yang tepat. Yield yang mendekati 100\% menunjukkan bahwa metode non-aqueous solvent evaporation yang digunakan dalam preparasi microspheres $\mathrm{MH}-\mathrm{EC}$ menghasilkan jumlah microspheres yang maksimal dengan efisien. Hilangnya sebagian microspheres yang mengakibatkan penurunan yield dapat disebabkan oleh proses penyaringan yang kurang tepat. ${ }^{16}$

Analisis FT-IR pada Gambar 5 sehingga preparasi microspheres tidak menganggu gugus spesifik dari $\mathrm{MH}$. Hal ini sejalan dengan penelitian yang dilakukan oleh Maji et $a l^{7}$ bahwa preparasi microspheres $\mathrm{MH}-\mathrm{EC}$ menunjukkan tidak adanya perubahan gugus fungsi yang khas pada $\mathrm{MH}$.

Ukuran partikel microspheres yang terbentuk dipengaruhi oleh banyaknya EC yang digunakan. Semakin besar konsentrasi
EC yang digunakan akan memperbesar ukuran partikel microspheres yang terbentuk. Hasil penentuan ukuran partikel didapatkan bahwa microspheres $\mathrm{MH}-\mathrm{EC}$ memiliki ratarata ukuran partikel $173,8 \pm 4,41 \mu \mathrm{m}$. Hal ini sesuai dengan persyaratan yang ditetapkan bahwa microspheres adalah partikel dengan rentang ukuran 1-1.000 $\mu \mathrm{m} .{ }^{17}$

Berdasarkan hasil karakterisasi tersebut maka preparasi microspheres $\mathrm{MH}-$ EC dengan metode non-aqueous solvent evaporation dapat dikatakan berhasil. Namun keberhasilan suatu preparasi microspheres juga perlu diikuti dengan pengujian biovailabilitas in vivo dan in vitro untuk mengetahui keberhasilan microspheres sebagai sistem penghantaran obat terkendali. Selain itu juga perlu dilakukan pengujian mutu sediaan untuk mengetahui stabilitas sediaan microspheres.

\section{Simpulan}

Hasil penelitian menunjukkan bahwa konsentrasi EC dan lama pengadukan terbukti memiliki pengaruh yang signifikan pada nilai EE microspheres $\mathrm{MH}-\mathrm{EC}$ yang dihasilkan. Kombinasi optimum antara konsentrasi EC dan lama pengadukan untuk memperoleh nilai EE maksimum adalah $4.500 \mathrm{mg}$ dan 2 jam.

\section{Ucapan Terima Kasih}

Penulis mengucapkan terima kasih kepada PT. Zenith Pharmaceutical, Semarang, Indonesia dan PT. Lawsim Zecha, Jakarta, Indonesia yang telah memberikan bantuan bahan aktif metformin hidroklorida dan polimer etil selulosa pada penelitian ini.

\section{Daftar Pustaka}

1. Nathan DM, Buse JB, Davidson MB. Management of hyperglycemia in type 2 diabetes: a consensus statement from 
the american diabetes association and the european association for the study of diabetes. Diab Care. 2009;32:193.

2. Pandit V, Pai RS, Yadav V, Devi K, Surekha B B, Inamdar MN, Suresh S. Pharmacokinetic and pharmacodynamic evaluation of floating microspheres of metformin hydrochloride. Drug Dev Indian Pharm. 2013;39(1):117-27.

3. Ghodake JD, Vidhate JS, Shinde DA, Kadam AN. Formulation and evaluation of floating microspheres containing anti-diabetic (metformin hydrochloride) drug. Int J Pharm Res. 2010;2(1):378-384.

4. Pilmore HL. Review: Metformin: Potential benefits and use in chronic kidney disease. Asian Sos Neph. 2010; 15:412-418.

5. Badoni A, Ojha A , Gnanarajan G, Kothiyal P. Review on Gastro Retentive Drug Delivery System. The Pharma Innovation. 2012; 1(8):32-42.

6. Behera AL, Patil SV, Sahoo SK. Formulation and characteristics of 5fluorouran cil microspheres by solvent evaporation method. Int $\mathbf{J}$ Pharm. 2011;3(1):32-35.

7. Maji R, Ray S, Das B, Nayak. Ethyl cellulose microparticles containing metformin hydrochloride by emulsification-solvent evaporation technique: effect of formulation variables. Int Sci. 2012;1-7.

8. Sappidi S, Thadkala K, Kota J, Aukunuru J. Preparation and characterization of ethyl cellulose microspheres encapsulating metformin hydrochloride and glipizide. Schol Res Lib. 2014;6(4): 213-226.
9. Li G, Liu G, Kang ET, Neoh KG, Yang X. Ph-responsive hollow polymeric microspheres from silicapolymer core shell microspheres. Nankai Univ. 2008;24(16):90509055.

10. Sweetman SC. Martindale $36^{\text {th }}$ ed. USA: Pharm Press; 2009.

11. Wells BG, Dipiro JT, Schwinghammer TL, Dipiro CV. Pharmacotherapy Handbook $9^{\text {th }}$ ed. USA: McGraw-Hill Education; 2015.

12. Bagul U, Gujar K, Dhat S, Aphale S, Bhavsar M. In vitro study of mucoadhesive strength of polymers for mucoadhesive drug delivery systems. Int J Pharm Res. 2009;1(1):42-46.

13. Rowe RC, Sheskey PJ, Quinn ME. Handbook of pharmaceutical excipient $6^{\text {th }}$ ed. London: Pharm Press and American Pharm; 2009.

14. Rathod UC, Patel AK, Shah DA. Statistical evaluation and optimization of influence of stirring speed and polymer concentration on hollow microspheres of diltiazem hydrochloride. Schol Res Lib. 2012; 4(3):972-978.

15. Garud N, Garud A. Preparation and in-vitro evaluation of metformin microspheres using non-aqueous solvent. Topic J Pharm Res. 2012 August;11(May):577-583.

16. Yadav A, Jain DK. Formulation and evaluation of gastroretentive floating microballoons of antidiabetic drug. Asian J Pharm Life Sci. 2011;1(2): 101-112.

17. Sahil K, Akanksha M, Premjeet S, Bilandi A, Kapoor B. Microsphere: A Review. IJRPC. 2011;1(4):1184-1198. 